\title{
An Exploration Of The Real Productivity Effects Of Cities\#
}

\author{
Michael S. Fogarty* and Gasper Garofalo**
}

\section{INTRODUCTION}

Recent evidence on earnings differentials between urban areas points to a tradeoff between income and environmental quality (Izraeli, 1977). Efforts to establish the characteristics of urban environmental qualityincome tradeoff functions must confront recent research dealing with the productivity of cities. A yet unresolved controversy exists between those who argue agglomeration economies produce a net productivity differential in favor of larger urban areas and those who suggest the higher incomes in larger cities largely reflect compensatory payments for urban disamenities. This paper attempts to resolve several parts of this controversy. First, it links the productivity-agglomeration argument with the amenitycompensation argument. A productivity effect of agglomeration economies affects the demand curve for labor, while an amenity effect of agglomeration economies affects the supply curve of labor. Second, the Segal production function model (1976), which identifies a significant 8 percent productivity threshold between SMSAs under 2 million and SMSAs over 2 million population, is respecified as a simultaneous model. A labor supply function, including an index of environmental quality as an independent variable affecting the position of the labor supply curve, is added to the Segal model. Although no evidence of a simultaneous bias is uncovered, it points to the shortcomings of existing research on the productivity of cities issue and identifies several major problems with the Segal model. Third, additional evidence is presented which identifies environmental quality-income tradeoff functions by level of education and position of life-cycle of the family head. Compensation for urban environmental disamenities is received only by the most mobile members of the labor force. Therefore, disaggregation of the labor supply function is necessary to identify characteristics of the environmental quality-income tradeoffs. To the extent that such tradeoff functions exist, it may be possible to interpret a new function based on the slope of the tradeoff functions as demand functions (marginal social benefit functions) for environmental quality.

\footnotetext{
\#Presented at 1978 Southern Regional Science Association Annual Meeting in Richmond, Virginia.

*Associate Professor of Economics and Research Associate, Regional Research Institute, West Virginia University. **Assistant Professor of Economics. Department of Economics. University of Akron.
} 


\section{THE PRODUCTIVITY OF CITIES ISSUE}

Most arguments dealing with issues of urban size and efficiency can be categorized as either productivity-agglomeration or amenitycompensation arguments. One major stumbling block preventing us from making a clearer statement on the benefits and costs associated with larger cities is the failure to link the two views. Additional empirical difficulties exist. Most importantly, differentials in hourly earnings between urban areas may in part reflect labor quality (including on-the-job training), cost-of-living, and capital stock per-worker differentials as well as disequilibrium in labor markets. This section outlines the current state of knowledge on the productivity-agglomeration and amenity-compensation arguments.

\section{Productivity-Agglomeration Arguments}

One of the first pieces of evidence suggesting the greater productivity of larger cities was presented by Fuchs (1967). Using a 1-1000 sample from the 1960 Census, Fuchs found that average hourly earnings increase substantially with urban size. The Fuchs urban hierarchy-wage function controls for age, race, sex, years of education, region, and cost-of-living. A more accurate statement on the Fuchs data is that the urban hierarchywage functions tend to be U-shaped, with wage declining through part of the size distribution of cities (e.g., for white males with 16 years of education and living in the North, a minimum wage is obtained in cities between 250,000 - 500,000 population in 1959).

Later research on the productivity issue appears to ignore the declining portion of the wage function and interprets the rising portion as evidence of greater productivity generated by agglomeration economies (Mera, 1973). Sveikauskas (1975) estimates that a doubling of urban size is typically associated with nearly a 6 percent increase in labor productivity. These estimates are obtained by examining a disaggregated industry level production function and are partially corrected for labor quality and cost-of-living differentials.

\section{Segal Production Function}

The strongest productivity argument is made by Segal (1976). Previous research may provide biased estimates of labor productivity because of a failure to control for differences in capital stock-per-worker. Segal partly overcomes this deficiency by estimating capital stock for 58 metropolitan areas. ${ }^{1}$ Because a modified version of the Segal production function is used in a later section, the Segal model is described here.

First, he assumes a production function of the following form:

$$
Q_{i}=A S^{\gamma} C_{i}{ }^{\delta} K_{i}{ }^{\alpha} L_{i}{ }^{\Sigma} \beta_{k\} \mid k}
$$


where

$\mathrm{Q}_{\mathrm{i}}=$ SMSA earnings corrected for cost-of-living differentials (1967);

A = transformation coefficient;

$\mathrm{S}=$ a dummy variable for size (SMSAs under 2 million population $=0$, and SMSAs over 2 million =1) $(1970)$;

$\mathrm{C}_{\mathrm{i}}=\mathrm{a}$ vector of site characteristics (climate, regional capital, and natural resources);

$\mathrm{K}_{\mathrm{i}}=$ estimated metropolitan capital stock;

$\mathrm{L}_{\mathrm{i}}=$ SMSA employment (1970);

$\mathrm{q}_{\mathrm{i}}=$ vector of labor quality variables (1970); and

$\gamma, \delta, \alpha, \beta,=$ elasticities.

Second, he assumes an identical production function for each urban size category. This implies constant returns to scale within each size category and an agglomeration effect operating through the size variable $S_{i}$. Third, he assumes that environmental characteristics can be controlled for by correcting SMSA earnings for cost-of-living differentials using urban population and region as proxies for environmental goods. Specifically, he estimates a comparative cost-of-living equation based on the comparative cost-of-living index for 38 SMSAs for a middle-class family of four using a regression equation of the following form: INDEX $=a+b_{1} P O P+b_{2} D N S$, where POP is 1970 SMSA population and DNS is a North-South dummy variable. The argument is that urban areas with superior environmental quality will attract a greater supply of labor, causing a lower wage and a lower price for locally-produced goods and services. Thus, he interprets the corrected earnings $Q_{\mathrm{i}}$ as "real" output in the sense that not only does it reflect a cost-of-living correction but that it also contains an environmental correction. Although there are several important issues involved in deriving this interpretation of the Segal production function, an obvious one is that he is assuming that environmental quality is a linear function of urban size. This is contrary to the expectation of other authors who anticipate disamenities being an increasing function of urban size (Baumol, 1967; Richardson, 1973).

Segal's most important finding is that $\gamma=.08$, which suggests a productivity threshold between areas under 2 million and areas over 2 million population. He argues that this is evidence of net agglomeration economies in the largest urban areas. To the extent that urban disamenities are an increasing function of urban size, Segal's production function would overestimate the "real" productivity differential. 


\section{Amenity-Compensation Arguments}

One possible interpretation of the Segal finding of an 8 percent productivity differential between the two urban size groups is that it merely reflects compensation for the disamenities associated with larger city size not captured by Segal's method of correcting for environmental quality. Hoch (1972), using a variety of approaches to control for characteristics of labor and cities, estimates that approximately $1 / 3$ of the size-related income differential is due to cost-of-living differences and $2 / 3$ is due to compensatory payments for disamenities. A more recent paper by Hoch and Drake (1974) extends the range of environmental characteristics affecting wage differentials to include climatic differences, but the essential argument remains unchanged. Izraeli (1977) pursues the amenitycompensation argument several steps further by taking into consideration the simultaneous relationship between prices and wages as well as the direct effect of environmental characteristics on both wages and prices. The results suggest that environmental variables (such as air pollution, local services, a hazard index, property tax, and climate) account for most of the observed variation in money wages.

Tobin and Nordhaus (1972) estimate that U. S. personal income data should be reduced by 8.7 percent, saying that the income data exaggerates the economic welfare of urban residents. Kelly (1977) responds to the Tobin-Nordhaus conclusion by formulating a simultaneous model of labor supply and labor demand estimated for 221 SMSAs in 1970. His labor supply equation includes SMSA population, percent urbanized population, and population density. His interpretation of the empirical results is that population and population density enter as amenities, while percent urbanized population is considered a disamenity. He concludes that the personal income statistic should be increased by 13.8 percent (rather than reduced by 8.7 percent) because the market wage is about 13.8 percent below the "real" wage. A closer look at the Kelly model indicates that he misinterprets the labor supply variables and does not successfully confront the environmental quality issue. However, he may have correctly observed that a simultaneous model is necessary to estimate the "real" productivity benefits of cities.

\section{PROBLEMS IN ISOLATING THE PRODUCTIVITY EFFECT OF AGGLOMERATION ECONOMIES}

Following Hoch's lead (1972), we can begin by assuming a demand curve for labor for each city. Each demand curve is assumed to be the value of the marginal product function derived from a production function similar to Segal's production function. We can then interpret the productivity effect of agglomeration economies as operating through the urban size variable. Thus, a larger urban area will possess a demand curve for labor which is positioned to the right of the demand curve for labor of smaller cities. We can also assume that the productivity effect of agglomeration economies 
diminishes with urban size. This is in line with the Baumol unbalanced growth argument (1967) which suggests activities can be divided into two categories: those that are technologically progressive (primarily the manufacturing sector) and those that are technologically stagnant (primarily the service sector). Since larger cities increasingly reflect the dominant role of service employment, we anticipate diminishing productivity gains from agglomeration economies. Therefore, bc is less than ab in Figure 1.

Figure 1: The Productivity Effect of Agglomeration Economies

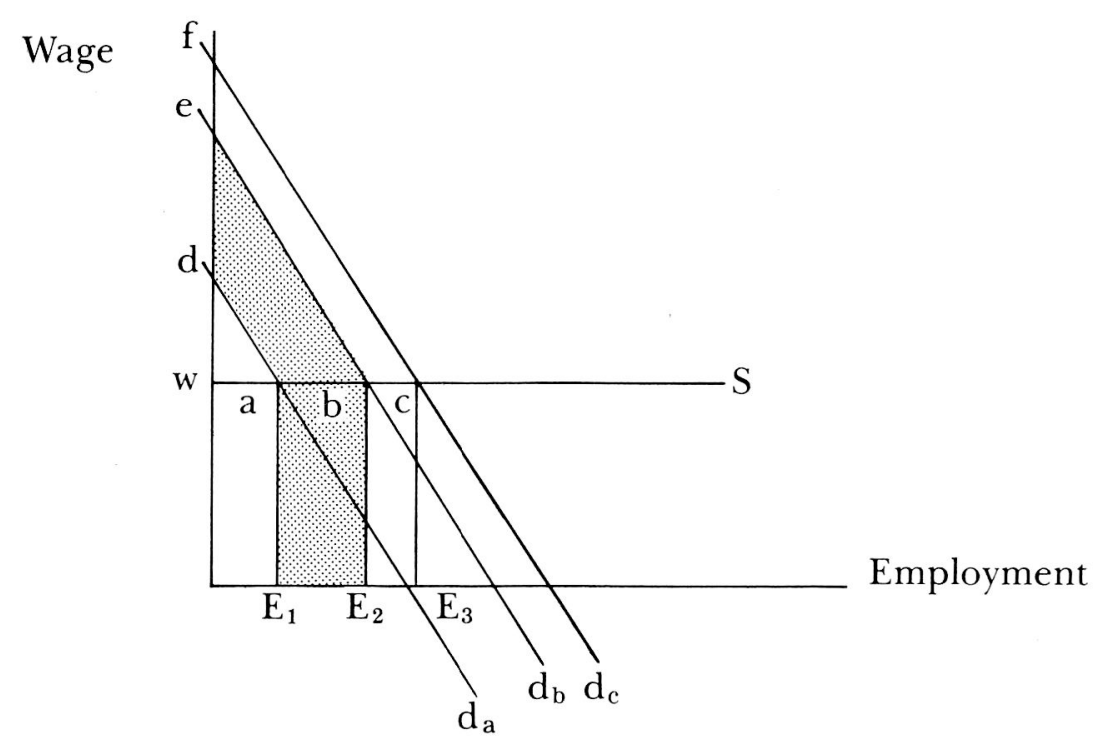

Figure 1 represents the simplest of all possible worlds. The labor supply function $S$ is perfectly elastic. In other words, there are no perceived environmental quality differences between City a, City b, and City c (a small, intermediate, and large city). In this particular case, we can consider changes in the area under the demand function (value of the marginal product functions) as the productivity effect of agglomeration economies since it represents the gain in urban output due purely to the influence of size (agglomeration economies). Thus the shaded area $\mathrm{E}_{1} \mathrm{E}_{2}$ bed is the productivity effect of City b over City a, and $\mathrm{E}_{2} \mathrm{E}_{3} \mathrm{cfe}$ is the productivity effect of City c over City b. A flat urban hierarchy-wage function is predicted. The picture becomes more complex when introducing environmental effects. Certain agglomeration economies affect the productivity of labor and thus shift the demand curve for labor. However, other agglomeration economies directly affect the amenity structure of a city and therefore can cause the labor supply function to shift. ${ }^{2}$ Each urban area can be characterized by three categories of amenities: (a) site-specific amenities such as nearness to beaches or mountains and climate; (b) size-related amenities such as ease of access to jobs, occupational choice, range of neighborhood choices, and information flows; and (c) purchased amenities such as high-quality shopping facilities, restaurants, quality of 
educational systems, and cultural activities. These three types of amenities give rise to an upward sloping labor supply curve which is unique for each city. Thus, each city's labor supply function at a point in time reflects the locational preferences for each city's unique bundle of environmental characteristics, including a size-preference. Employment of additional members of the labor force will require the payment of a compensating wage differential.

\section{Productivity Effect With Positive Amenities: Case 1}

A comparison of City b with City a suggests a higher income level in City $b$ because City b contains a higher ratio of skilled to unskilled labor. The higher income level in City b produces a favorable change in the amenity structure through an income effect on purchased amenities. Consequently, at each wage more persons will prefer to live and work in City b. A stronger amenity effect will produce a supply function positioned further to the right. Thus, Figures 2 and 3 include both a productivityagglomeration effect and an amenity-compensation effect.

The productivity effect of agglomeration economies is given by area cdfgh in Figure 2. It represents the extra value of urban product assuming no change in the amenity structure. The amenity effect of agglomeration economies is given by the shaded area deif. It represents the change in the value of urban product assuming a more favorable amenity structure in City $b$ because of a positive change in purchased amenities.

Figure 2: Productivity Effect With Positive Amenities

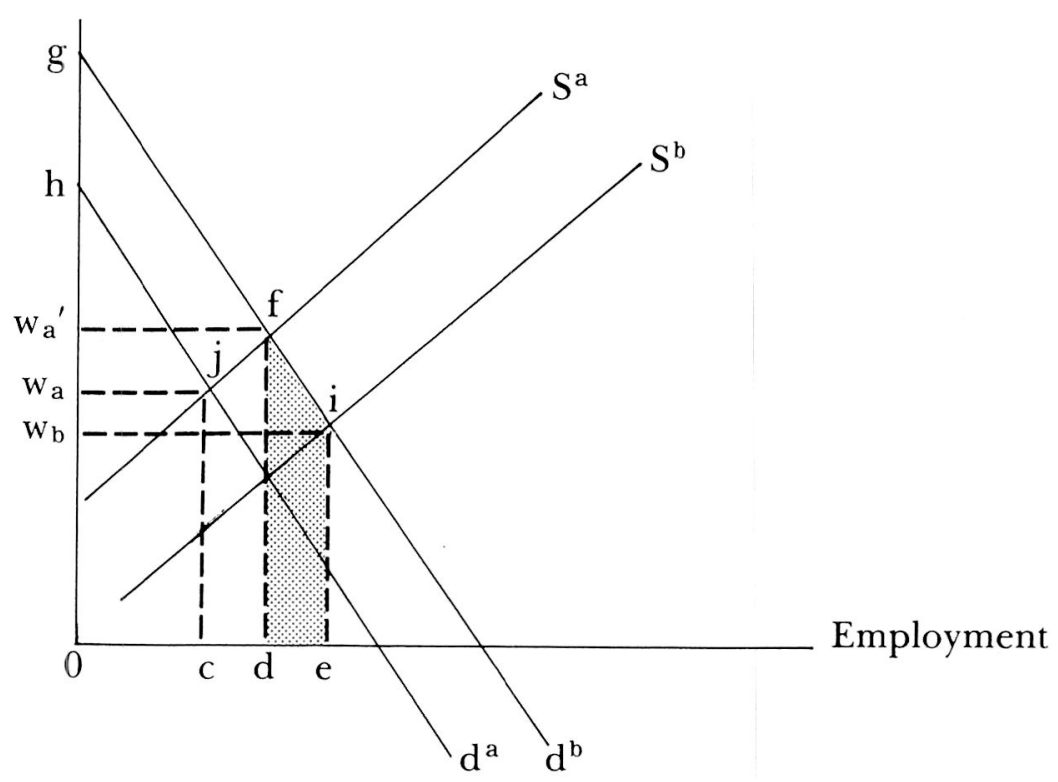


Since $\mathrm{w}_{\mathrm{b}}$ is less than $\mathrm{w}_{\mathrm{a}}$, this case is consistent with the declining portion of the hierarchy-wage function. The observed change in the value of urban product is given by the full change in the area under the demand function, or ceigh. In such a case a Segal model would tend to overestimate the productivity effect of agglomeration economies and ignore the amenity effect.

\section{Productivity Effect With Negative Amenities: Case 2}

Figure 3 can be considered a comparison between the intermediate-size and large city. An unfavorable change in the amenity structure is anticipated. The higher income in City c generates significant market failure problems so that net disamenities are produced. Consequently, $\mathrm{S}_{\mathrm{c}}$ is positioned to the left of $S_{b}$-fewer workers are willing to live and work in City c at each wage.

Figure 3: Productivity Effect With Negative Amenities

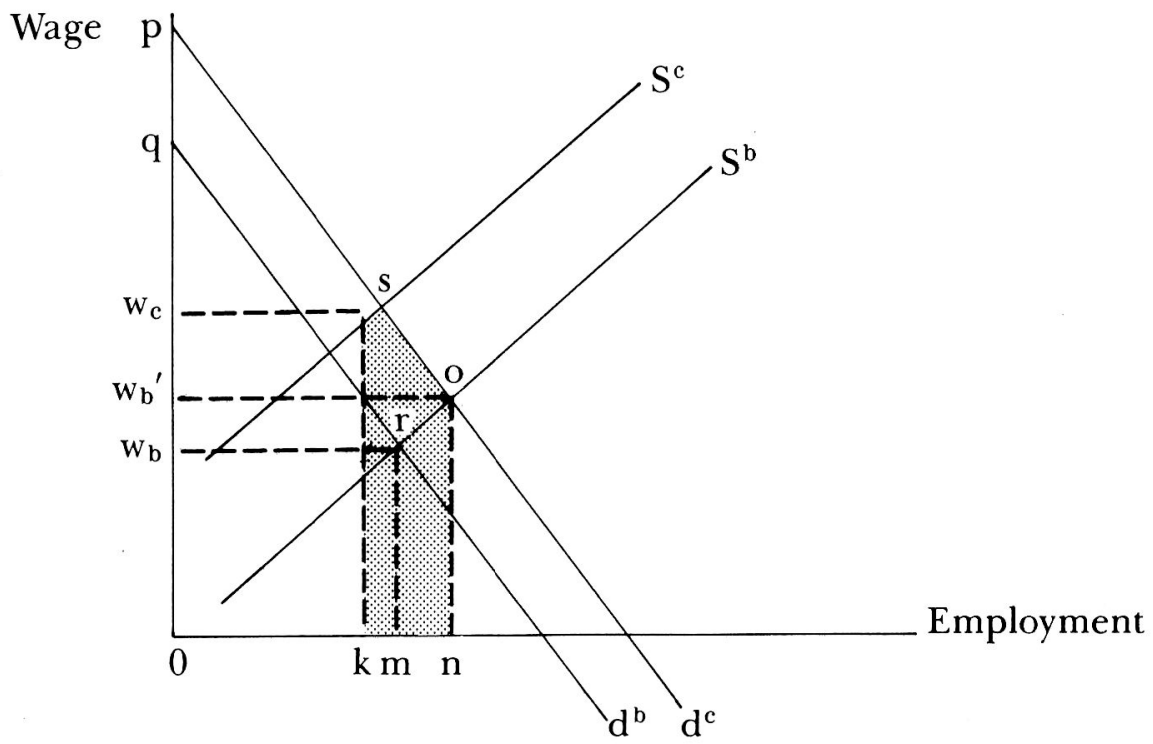

The productivity-agglomeration effect is given by area mnopqr. The amenity-compensation effect is given by the shaded area knos. The latter represents the loss in urban output because of a less favorable amenity structure in City c created by negative changes in purchased amenities. Since $w_{c}$ exceeds $w_{b}$, this case is consistent with the rising portion of the hierarchy-wage function. The observed change in the value of urban product is given by omrq - oksp. In such a case a Segal model would tend to underestimate the productivity effect of agglomeration economies and ignore the amenity effect of agglomeration economies. Also, if knos > (onmr + opqr), then environmental decay associated with urban size imposes a net loss on society. The particular case cited above also indicates a 
net loss in employment equal to $\mathrm{km}$. Such a city would have difficulty maintaining its size.

To summarize, previous research on the efficiency of larger cities has stressed either the productivity effect of agglomeration economies or the disamenity effects associated with size. The two views must be merged. Segal's model ignores the possibility that labor supply functions may be upward sloping and may shift in response to environmental changes. Changes in urban output are the sum of two separate effects: the productivity effect of agglomeration economies and the amenity effect of agglomeration economies. The view presented above suggests a U-shaped wage function consistent with the findings of Fuchs. The declining portion of the hierarchy-wage function is the result of a favorable change in the amenity structure. The upward-sloping portion of the hierarchy-wage function is the result of an unfavorable change in the amenity structure. The Segal model can be respecified as a simultaneous model, including at a minimum both a labor demand and a labor supply function. An environmental determination equation can also be added to take into account the effect of wages on environmental quality.

\section{A TEST OF THE REAL PRODUCTIVITY EFFECTS OF URBAN SIZE WITH A LABOR SUPPLY FUNCTION}

This section estimates a modified version of the Segal production function. The model is modified in two ways. First, the variables included in the Segal production function are not identical. A manufacturing dummy variable is included in the production function to correct for a tendency for Segal's capital stock variable to underestimate the capital stock in manufacturing cities. ${ }^{3}$ Because the form of the model presented here represents a first effort, two variables are excluded-the regional capital and employment in mining variables. Second, a labor supply function is introduced. The labor supply function incorporates features of the amenity-compensation argument in that it includes environmental variables. The most important environmental variable is the Liu index (represented by ENV in the labor supply function).

\section{The Liu Quality-of-Life Index}

The Liu index is based on approximately 120 measures of environmental quality (social indicators) for each of 243 SMSAs in 1970. The index has five components: economic (ECON), political (EPOL), environmental (ENV), health and education (HENV), and social (ESOC). Each separate index is computed by categorizing variables and assigning them equal weight. For example, if we assume the ENV index includes only measures of climate and pollution but there are five measures of climate and three measures of pollution, then climate and pollution are each given a weight of .50 in ENV. However, each separate variable describing pollution receives a weight of $1 / 3$, and each separate variable describing climate re- 
ceives a weight of $1 / 5$. This represents an effort to avoid double-counting. An overall index is computed as simply the sum of each of the five separate components and is considered an overall quality of life index (QOL). Each of the five separate components is assigned equal weight. The mean for all SMSAs in three separate size groups (small, intermediate, and large) is then computed. Standardized scores are constructed where the average SMSA in each size category has a value of 1.0. The ENV component of the index is used in the labor supply function, while the QOL is used in the last section of the paper.

\section{A Segal Model With Labor Supply}

The modified Segal demand function is given as follows:

$$
\begin{aligned}
& \mathrm{Q}=\mathrm{A} \mathrm{ED}^{\gamma_{1}} \mathrm{AGE}^{\gamma_{2}} \mathrm{MAN}^{\gamma_{3}} \operatorname{POP}^{\gamma_{4}} \mathrm{k}^{\delta} \mathrm{L}^{\beta}, \\
& \text { if } \frac{\partial Q}{\partial \mathrm{L}}=\mathrm{w}=\beta \mathrm{A} \mathrm{ED}^{\gamma_{1}} \quad \mathrm{AGE}^{\gamma_{2}} \quad \mathrm{MAN}^{\gamma_{3}} \quad \operatorname{POP}^{\gamma_{4}} \mathrm{k}^{\delta} \mathrm{L}^{\beta-1} \\
& =\beta \mathrm{AED}^{\gamma_{1}} \quad \mathrm{AGE}^{\gamma_{2}} \quad \mathrm{MAN}^{\gamma_{3}} \quad \mathrm{POP}^{\gamma_{4}} \mathrm{k}^{\delta} \mathrm{L}^{\delta+\beta-1}
\end{aligned}
$$

Then $\log \mathrm{w}=\log (\mathrm{A}+\beta)+\gamma_{1} \log \mathrm{ED}+\gamma_{2} \mathrm{AGE}+\gamma_{3} \mathrm{MAN}+\gamma_{4} \mathrm{POP}$ $+\delta \log \mathrm{k}+(\delta+\beta-1) \log \mathrm{L}$.

Therefore, the labor demand and labor supply equations to be estimated are:

Demand: $\quad \log \mathrm{w}_{=}=\mathrm{a}_{\mathrm{o}}+\mathrm{a}_{1} \log \mathrm{ED}+\mathrm{a}_{2} \log \mathrm{AGE}+\mathrm{a}_{3} \mathrm{MAN}+\mathrm{a}_{4}$ POP $+\mathrm{a}_{5} \log \mathrm{k}+\mathrm{a}_{6} \log \mathrm{L}$,

Supply: $\quad \log \mathrm{L}=\mathrm{b}_{0}+\mathrm{b}_{1} \log \mathrm{w}+\mathrm{b}_{2} \mathrm{MAN}+\mathrm{b}_{3} \mathrm{POP}+\mathrm{b}_{4} \mathrm{DNS}+\mathrm{b}_{5} \log \mathrm{U}$ $+\mathrm{b}_{6} \log \mathrm{ENV}$

where

$Q_{\mathrm{i}}$ is SMSA earnings corrected for cost-of-living differentials in $1967^{4}$;

ED is median years of education in 1970 ;

AGE is median years of age in 1970 ;

MAN is a manufacturing dummy variable $(1=$ cities with 30 percent or more of earnings received from the manufacturing sector, $1967 ; 0=$ otherwise);

POP is a population dummy variable $(1=$ SMSAs with population exceeding 2 million in 1970; $0=$ otherwise); 
$\mathrm{k}$ is the capital to labor ratio;

$\mathrm{L}$ is the number of employed persons in the SMSA in 1967;

A is a transformation coefficient;

DNS is a North-South dummy variable $(1=$ South; $0=$ North $)$;

$\mathrm{U}$ is the SMSA unemployment rate in 1970;

$\mathrm{ENV}$ is the environmental component of the Liu index (where the index $\mathrm{ENV}$ is to be interpreted as higher ENV is associated with lower environmental quality).

A test of constant returns to scale is provided by the coefficient on L;

$$
\begin{aligned}
& \text { if } \mathrm{a}_{6}=1, \text { then } \delta+\beta=1 \text { (constant) } \\
& \text { if } \mathrm{a}_{6}>1, \text { then } \delta+\beta>1 \text { (increasing) } \\
& \text { if } \mathrm{a}_{6}<1, \text { then } \delta+\beta<1 \text { (decreasing). }
\end{aligned}
$$

The modified Segal production function produces results comparable to Segal's but with nearly a 10 percent size effect rather than an 8 percent size effect. This is shown by the coefficient on the POP variable. The difference can be attributed to the exclusion of regional capital and mining employment variables, and the inclusion of a manufacturing dummy variable to correct the capital stock estimates. A comparison of the OLS estimates of the labor demand equation with 2SLS estimates indicates there is no apparent simultaneous bias in the Segal model. The coefficients are nearly identical for both forms. In particular, the size effect remains essentially unchanged. A glance at the labor supply equation in Table 2 provides some insight into the reason for the stability of the estimated coefficients. First, the labor supply function is highly elastic. Second, and most important, the Liu index (ENV) is insignificant and has a very small coefficient.

The results could be interpreted as support for Segal's estimates of the productivity threshold (as well as the lack of support for increasing returns to scale since $a_{6}$ is not significantly different from zero, where $a_{6}$ is the coefficient on $\mathrm{L}$ and $=\delta+\beta-1$ ). However, several observations suggest that an alternative specification of the model may lead to a new conclusion. First, the model should be disaggregated by skill or level of education and by age of household head (position in the family life-cycle). In other words, the ability to obtain a compensating wage differential for urban disamenities is dependent on mobility. Thus, we should observe the steepest labor supply functions and greatest shifts in supply in response to environmental changes for those with the highest levels of education in the most mobile portion of the life-cycle. Empirical evidence supporting this 
TABLE 1

Labor Demand Equations Estimated

With OLS and 2SLS

\begin{tabular}{lcc}
\hline Variables & OLS & 2 SLS \\
\hline $\mathrm{a}_{0}$ Constant & 8.1854 & 8.1970 \\
& $(8.1678)$ & $(8.175)$ \\
$\mathrm{a}_{1} \mathrm{ED}$ & .5779 & .5664 \\
& $(1.72)$ & $(1.69)$ \\
$\mathrm{a}_{2} \mathrm{AGE}$ & -.2783 & -.2770 \\
& $(2.30)$ & $(2.29)$ \\
$\mathrm{a}_{3}$ MAN & .0308 & .0317 \\
& $(1.503)$ & $(1.544)$ \\
$\mathrm{a}_{4}$ POP & .0993 & .0924 \\
& $(2.546)$ & $(2.340)$ \\
$\mathrm{a}_{5} \mathrm{k}$ & .0835 & .0799 \\
& $(1.907)$ & $(1.820)$ \\
$\mathrm{a}_{6} \mathrm{~L}$ & -.0141 & -.0099 \\
& $(0.7015)$ & $(0.4799)$ \\
$\mathrm{RSQD}$ & .40 & .40 \\
$\mathrm{~F}$ & 5.63 & 4.82 \\
\hline
\end{tabular}

point is contained in the following section. Second, a proper specification of the model should be dynamic. For example, output in period $t$ is a function of inputs in period t, but labor supply is a function of wages and environment in some previous period t-1. Also, income is expected to have an impact on environmental quality, but with a time lag to $t+1$. Such a dynamic model of environmental quality and urban income has yet to be investigated. Third, there are problems with the Liu index. The index lumps together an array of characteristics assuming each characteristic deserves equal weight; in other words, a unit's change in substandard housing is equally valued with a unit's change in any other characteristic, such as pollution. In terms of picking up compensation for disamenities, the index more or less assumes an even spatial distribution of environmental amenities and disamenities within each SMSA. Hence, for a given value of $\mathrm{ENV}$, it is assumed to be equally costly to purchase isolation from disamenities. Finally, a more complete specification of site-specific amenities is necessary. In sum, additional research is warranted.

\section{E-Y TRADEOFF FUNCTIONS AND DEMAND FUNCTIONS FOR ENVIRONMENT}

One way of establishing the existence of an environmental qualityincome tradeoff (E-Y) is to look more carefully at the sensitivity of family 
TABLE 2

Labor Supply Equations

Estimated With 2SLS

\begin{tabular}{lc}
\hline Variables & 2 SLS \\
\hline $\mathrm{b}_{0}$ Constant & -38.64 \\
& $(1.936)$ \\
$\mathrm{b}_{1} \mathrm{w}$ & 4.859 \\
& $(2.253)$ \\
$\mathrm{b}_{2}$ MAN & -.5068 \\
& $(2.750)$ \\
$\mathrm{b}_{3}$ POP & 1.226 \\
& $(4.419)$ \\
$\mathrm{b}_{4}$ DNS & -.1529 \\
& $(0.6649)$ \\
$\mathrm{b}_{5} \mathrm{u}$ & -.3852 \\
& $(1.062)$ \\
$\mathrm{b}_{6}$ ENV & .0057 \\
& $(.0226)$ \\
$\mathrm{RSQD}$ & .62 \\
$\mathrm{~F}$ & 11.88 \\
\hline
\end{tabular}

income to urban environmental quality differentials by level of education and age of the family head. First, Figure 4 depicts an E-Y function for a particular family group. The E-Y function can be considered an indifference curve which reflects an equilibrium tradeoff between environmental quality and income such that the family is indifferent between points a, b, c, and $d$. The slope of $E-Y$ increases in moving to lower $E$, indicating higher valuation of $\mathrm{E}$ at lower environmental quality levels. Second, the slope of the $\mathrm{E}-\mathrm{Y}$ function $\mathrm{d} \mathrm{Y} / \mathrm{dE}$ measures the extra income a family is compensated for living in a less preferred urban area. Alternatively, the function $\mathrm{dY} / \mathrm{dE}$ can be considered a "willingness-to-pay" function (the extra income a family is willing to give up to live and work in a more preferred urban area).

Therefore, when summed over all population groups, dY/dE might be viewed as a demand curve for urban environmental quality (marginal social benefit function). Third, if such a function exists, we can obtain estimates of the value of particular improvements in the environment by estimating the area under the MSB function.

Consider $Y_{i}=A E_{i}^{a} X_{i}^{b}$ as the E-Y tradeoff function, where $Y_{i}$ is mean family income for a particular education-age group (adjusted for cost-ofliving differentials); $E_{i}=$ an index of urban environmental quality; $X_{i}=a$ vector of population and site characteristics affecting $Y_{i}$; and $A, a$, and $b$ 
Figure 4: Hypothetical

E-Y Function

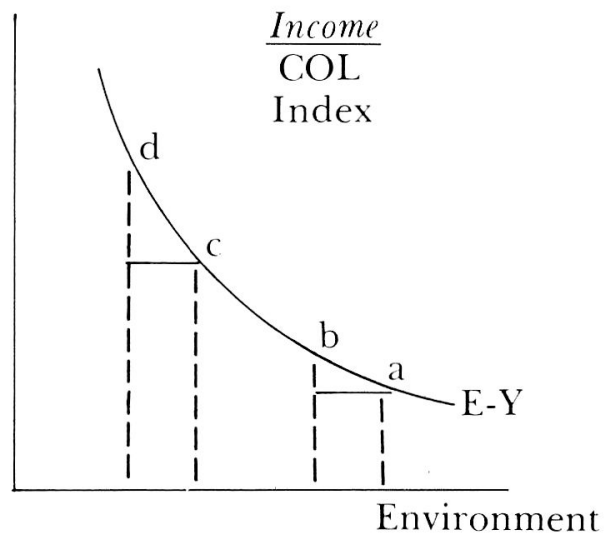

Figure 5: Hypothetical Demand for Environment Function

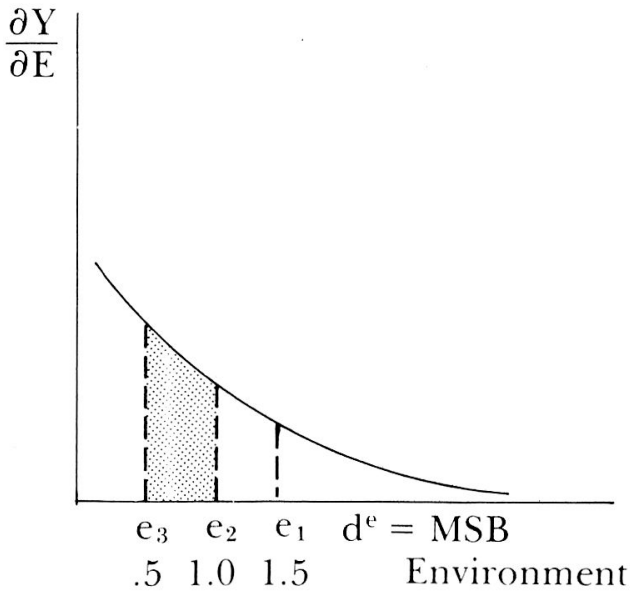

are constants. Then, $\partial \mathrm{Y} / \partial \mathrm{E}=\mathrm{aAX}_{\mathrm{i}}^{\mathrm{b}} \mathrm{E}_{\mathrm{i}}^{\mathrm{a}-1} \quad$ is the MSB function. Thus, the value of a particular improvement can be evaluated as a change in the area under $\partial \mathrm{Y} / \partial \mathrm{E}$, or

$$
\mathrm{Y}^{*}=\int_{\mathrm{e} 3}^{\mathrm{e}_{2}} \mathrm{aAX}_{\mathrm{i}}^{\mathrm{b}} \mathrm{E}_{\mathrm{i}}^{\mathrm{a}-1} \mathrm{dE}=\mathrm{AX} \mathrm{X}_{\mathrm{i}}^{\mathrm{b}} \int_{\mathrm{e} 3}^{\mathrm{e}_{2}} \mathrm{E}_{\mathrm{i}}^{\mathrm{a}} \mathrm{dE}
$$

$\mathrm{Y}^{*}$ is indicated by the shaded area in Figure 5. We can interpret $\mathrm{AX}_{\mathrm{i}}^{\mathrm{b}}$ as the uncompensated income for group $\mathrm{i}$ (which is also the mean family income of $\mathrm{i}$ in an urban area with average environmental quality) and $\mathrm{E}_{\mathrm{i}}^{\mathrm{a}}$ as the environmental compensation effect.

\section{Estimated E-Y Functions}

E-Y functions were estimated for each of nine levels of education of the family head and for five age groups. ${ }^{5}$ The sample is composed of the 33 SMSAs with population over 250,000 for which we have comparative cost-of-living data (the SMSAs are listed in Appendix A). ${ }^{6}$ The function to be estimated is given as follows:

$$
\mathrm{Y}_{\mathrm{i}}=\mathrm{AE}_{\mathrm{i}}^{\mathrm{a}} \mathrm{P}_{\mathrm{i}}^{\mathrm{b}} \mathrm{B}_{\mathrm{i}}^{\mathrm{c}} \mathrm{U}_{\mathrm{i}}^{\mathrm{d}} \mathrm{GR}_{\mathrm{i}}^{\mathrm{f}} \mathrm{DNS},
$$

where $\quad Y_{i}=$ mean family income, 1970 (corrected for cost-of-living differences as estimated by the Department of Labor);

$\mathrm{E}_{\mathrm{i}}=$ overall quality-of-life index, 1970 (Liu QOL index);

$\mathrm{P}_{\mathrm{i}}=$ SMSA population, 1970 ;

$\mathrm{B}_{\mathrm{i}}=$ percent black population in the SMSA, 1970;

$\mathrm{U}_{\mathrm{i}}=$ SMSA unemployment rate, 1970; 
$\mathrm{GR}_{\mathrm{i}}=$ population growth rate, 1960-70; and

DNS $=$ North-South Dummy Variable $(1=$ South; $0=$ North $)$.

Table 3 presents the estimated elasticities for the environmental variable. Other variables are viewed simply as control variables. First, the total model lumps together all families and does not control for level of education or position in the family life-cycle. Therefore, this form of the regression model provides estimates that are comparable to the labor quantity used in the modified Segal model. The elasticities are insignificant except for the age groups 55-64 and 65 and over. The latter have incorrect signs and may in part be due to the choice of favorable environments by higherincome elderly. Second, the amenity-compensation effect is evident for families with the greatest amount of education and in the most mobile period of the family life-cycle. This is shown by the negative and significant elasticities for families headed by a person with more than a high school degree and primarily in the age groups 25-34, 35-44, and 45-54. No amenity compensation effect is indicated for families headed by a person with less than a high school degree. Consequently, it is not surprising that

TABLE 3

Income-Environmental Quality Elasticities by Level of Education and Age of Family Head, 1970

\begin{tabular}{|c|c|c|c|c|c|}
\hline \multirow{2}{*}{$\begin{array}{l}\text { Years of Education } \\
\text { of Family Head }\end{array}$} & \multicolumn{5}{|c|}{ Age of Family Head } \\
\hline & $25-34$ & $35-44$ & $45-54$ & $55-64$ & $65+$ \\
\hline Total & -.033 & -.010 & .018 & $.091 * *$ & $.125^{* *}$ \\
\hline \multicolumn{6}{|l|}{ College } \\
\hline 5 yrs. or more & $-.074 * *$ & $-.056^{*}$ & $-.060 *$ & .028 & $.210 * *$ \\
\hline 4 years & $-.084 * *$ & $-.068^{*}$ & -.045 & .052 & .015 \\
\hline $1-3$ years & $-.103 * *$ & $-.117 * * *$ & $-.095 * *$ & $-.081^{*}$ & .075 \\
\hline \multicolumn{6}{|l|}{ High School } \\
\hline 4 years & -.067 & $-.080 *$ & $-.080 * *$ & -.008 & $-.067 *$ \\
\hline $1-3$ years & -.062 & -.033 & -.034 & -.013 & .028 \\
\hline \multicolumn{6}{|l|}{ Elementary School } \\
\hline 8 years & -.051 & -.032 & -.023 & $\mathrm{NA}$ & NA \\
\hline 5-7 years & -.013 & -.020 & -.022 & .024 & .027 \\
\hline Less than 5 years & .100 & -.014 & .057 & $.104 *$ & .036 \\
\hline
\end{tabular}


the labor supply function in the modified Segal model performs so poorly. A disaggregated form of the modified Segal model should reveal the E-Y tradeoff and reduce the estimates of the "real" productivity for cities over 2 million population. This also represents evidence that the social costs of urban environmental decay are disproportionately borne by the urban poor. The poor are unable to obtain compensation for urban disamenities. It also provides more direct evidence that urban environmental decay in larger cities is an important and overlooked source of inequality in urban income distribution. ${ }^{7}$

\section{Estimating Environmental Demand Functions}

Finally, to illustrate the potential policy applications of E-Y functions, we can look at the estimated E-Y function for one particular group (college graduates in the age group 25-34):

$$
\mathrm{Y}_{\mathrm{i}}=9421 \mathrm{E}_{\mathrm{i}}^{-.0839} \mathrm{P}_{\mathrm{i}}^{.0234} \mathrm{~B}_{\mathrm{i}}^{.0089} \mathrm{U}_{\mathrm{i}}^{-.0751} \mathrm{GR}_{\mathrm{i}}^{.0092} \text { DNS } \quad \mathrm{R}^{2}=.65
$$

Since $\mathrm{Y}^{*}=\mathrm{AX}_{\mathrm{i}}^{\mathrm{b}} \int_{\mathrm{e} 3}^{\mathrm{e} 2} \mathrm{E}_{\mathrm{i}}^{\mathrm{a}} \mathrm{dE}$, then we can evaluate particular changes in environment for this group. For example, we can determine the value of a change in the Liu index of environmental quality from .5 to 1.0 and from 1.0 to 1.5 as follows:

$$
\begin{aligned}
& \mathrm{Y}^{*}=10574 \int_{.5}^{1.0} \mathrm{E}_{\mathrm{i}}^{-.0839} \mathrm{dE}=10574(-.0599)=-\$ 633 \text { and } \\
& \mathrm{Y}^{*}=10574 \int_{1.0}^{1.5} \mathrm{E}_{\mathrm{i}}^{-.0839} \mathrm{dE}=10574(-.0376)=-\$ 357 .
\end{aligned}
$$

The function $\mathrm{Y}^{*}$ is evaluated for an SMSA with a population of 2 million and mean values for $\mathrm{B}=10.66, \mathrm{U}=4.27, \mathrm{GR}=20.0$, and located in the North. Note that 10574 is the uncompensated mean family income (corrected for cost-of-living differentials), and the value of $\mathrm{E}_{\mathrm{i}}{ }^{-.0839}$ is the amenity-compensation effect for this group. Although these estimates are purely illustrative, they represent estimates of the areas under MSB in Figure 5 and are interpreted as the estimated annual benefits to families in this group from altering environmental quality by the specified amounts. The total benefits can be obtained by taking the estimated functions for each group, then perform the above calculation, and multiply the amounts by the number of families in each education-age group.

\section{CONCLUSIONS}

A fair evaluation of the efficiency of larger cities must be based on the "real" productivity effects of cities. First, on a theoretical level, we anticipate a productivity-agglomeration and amenity-compensation effect associated with urban size. A U-shaped urban hierarachy-wage function suggests the amenity-compensation effect is positive through a significant portion of the city size distribution (i.e., initially there is greater productivity and a more favorable amenity structure). The rising portion of the 
hierarchy-wage function points to an increasingly important role played by urban disamenities.

Second, while it is possible to isolate the productivity-agglomeration and amenity-compensation effects graphically, empirical identification is elusive for a variety of reasons, not the least of which is the problem of measuring environmental quality. The Segal production function model identifies an 8 percent productivity threshold between SMSAs under 2 million and over 2 million population. Segal interprets the 8 percent differential as a "real" productivity differential, assuming an urban size cost-of-living correction of earnings adequately controls for urban amenities and disamenities. A modified version of the Segal model attempts to empirically isolate the amenity-compensation effect by incorporating a labor supply function and treating the model as simultaneous. The labor supply function includes a measure of environmental quality (the Liu index). The results do not alter the Segal urban size productivity estimate.

Third, one major problem with the latter model is the anticipation that only the most mobile members of the labor force (those with the greatest amount of education and in the most mobile period of the family life-cycle) will be able to obtain compensation for disamenities. This expectation is supported with evidence based on environmental quality-income elasticites estimated from a single equation regression model for families disaggregated by years of education and age group of the household head. These estimated functions are interpreted as environmental qualityincome tradeoff functions. Potential policy applications are suggested. A function based on the slope of the E-Y function is treated as a demand function for environmental quality, and total family benefits of environmental improvement can be estimated as the area under such demand functions evaluated over a specific range of environmental quality.

Finally, additional research on utilizing a disaggregated labor supply function may substantially reduce the estimated 8 percent "real" productivity differential. Also, the model can be improved by being specified as a dynamic model, allowing the effects of environment on adjustments in the labor force and income on environment to occur with time lags.

\section{FOOTNOTES}

\footnotetext{
${ }^{1}$ The method for estimating urban capital stock is a standard investment approach introduced by Solow (1962) and is described in Segal (1976, pp. 343-344). All estimates are deflated for inter-city construction cost differentials.

${ }^{2}$ There is no general agreement on the nature of agglomeration economies. The concept of agglomeration economies used here is in the spirit of the broad framework developed by Richardson (1973) Richardson outlines three categories of agglomeration economies: social agglomeration economies which include public service efficiency and intra-regional spatial structure, household agglomeration economies which include urban amenities, and business agglomeration economies which include business services, market potential, transportation cost savings, etc.

${ }^{3}$ Cities with a large manufacturing sector have lower
}

capital-labor ratios than non-manufacturing cities. It appears that for given wages and capital stock the number of employed persons in manufacturing cities is lower than for non-manufacturing cities. This bias is consistent with all manufacturing cities. This contradicts traditional economic theory which implies that the manufacturing sector tends to have high capital-labor ratios, given the ease of substitutability of capital for labor when wages increase. One reason for the bias is that capital stock in the manufacturing sector is based on recent investment in that sector. Since older industrial cities have had little recent investment, the capital stock in manufacturing is substantially underestimated. Segal's model would tend to overstate the productivity effect of agglomeration economies to the extent that the capital stock is underestimated.

${ }^{4}$ Segal's $Q_{i}$ underestimates total output since it does 
not include interest, rent, and profit earned in each SMSA. The coefficients will tend to be biased to the extent that labor's share is not constant across the size distribution of cities.

${ }^{5}$ Age-income profile data for SMSAs with population over 250,000 are available from the U. S. Bureau of Census, Detailed Characteristics of the Population, 1970 , Table 202.

${ }^{6}$ An effort was made to expand the size of the sample to include all SMSAs with population over 250,000 by estimating the cost-of-living index with the Segal costof-living equation but for each of three standards-ofliving. The Segal estimating equation proved to be a poor predictor of cost-of-living differentials in a significant number of cases. Consequently, it was decided to limit tests to the thirty-three SMSAs.

${ }^{7}$ Gasper Garofalo and Michael S. Fogarty, "Urban Income Distribution and the Urban Hierarchy-Equality Hypothesis," Review of Economics and Statistics, August 1979, pp. 381-387.

\section{REFERENCES}

Baumol, W. J., "Macroeconomics of Unbalanced Growth: The Anatomy of Urban Crisis," American Economic Review 57 (1967).

Fuchs, Victor R., "Differentials in Hourly Earnings by Region and Size, 1959," National Bureau of Economic Research Occasional Paper No. 101, New York, 1967.

Hoch, Irving, "Income and City Size," Urban Studies 9 (October 1972).

Hoch, Irving and Drake, Judith, "Wages, Climate and the Quality of Life," Journal of Environmental Economics and Management 1 (1974), pp. 268-295.

Izraeli, O., "Differentials in Nominal Wages and Prices Between Cities," Urban Studies 14 (October 1977).

Kelly, K. C., "Urban Disamenities and the Measure of Economic Welfare," Journal of Urban Economics 4 (October 1977), pp. 379-388

Liu, Ben-Chieh, Quality of Life Indicators in the U.S.Metropolitan Areas, 1970 (Summary) (Kansas City: Midwest Research Institute, 1975).
Mera, Koichi, "Urban Agglomeration and Economic Efficiency," Economic Development and Cultural Change 21 (January 1973).

Nordhaus, W. and Tobin, J., "Economic Growth," National Bureau of Economic Research Fiftieth Anniversary Colloquium, Vol. V, Columbia University Press, New York (1972).

Richardson, Harry W., The Economics of Urban Size (Lexington, Mass.: Lexington Books, 1973).

Segal, David, "Are There Returns to Scale in City Size?" Review of Economics and Statistics 53 (August 1976), pp. 339-350.

Solow, R. M., "Technical Progress, Capital Formation, and Economic Growth," American Economic Review 52 (1962).

Sveikauskas, Leo, “The Productivity of Cities, " Quarterly Journal of Economics 89 (August 1975).

\section{APPENDIX A}

List of SMSAs Used in Modified Segal Model and Environmental Quality-Income Tradeoff Functions

\section{Modified Segal Model (57 SMSAs):}

Erie, PA

Reading, PA

Lancaster, PA

Utica-Rome, NY

Peoria, IL

Wilkes-Barre-Hazleton, PA

Davenport-Rock Island-Moline, IA-IL

Canton, $\mathrm{OH}$

Wichita, KS

Tulsa, OK

Flint, MI

Richmond, VA

Springfield-Chicopee-Holyoke, MA-CT

Youngstown-Warren, $\mathrm{OH}$

Grand Rapids, MI

Nashville, Davidson, TN

Allentown-Bethlehem-Easton, PA-NJ

Syracuse, NY

Akron, $\mathrm{OH}$
Toledo, OH-MI

Albany-Schenectady-Troy, NY

Birmingham, AL

Fort Worth, TX

Memphis, TN-AR

Louisville, KY-IN

Dayton, $\mathrm{OH}$

Rochester, NY

Columbus, $\mathrm{OH}$

Phoenix, AZ

Portland. OR-WA

Tampa-St. Petersburg. FL

New Orleans. I.A

San Jose. C.A

Indianapolis. IN

San Bernardino-Riverside-Ontario, (A

Denver. (C)

Kansas (itv, MO-KA

Buffalo. NY 
Cincinnati, OH-KY-IN

Atlanta, GA

Milwaukee, WI

Seattle-Everett, WA

Dallas, TX

Minneapolis-St. Paul, MN

Houston, TX

Cleveland, $\mathrm{OH}$

Baltimore, MD

St. Louis, MO-IL
Pittsburgh, PA

Boston, MA

Washington, DC-MD-VA

San Francisco-Oakland, CA

Detroit, MI

Philadelphia, PA-NJ

Chicago, IL

Los Angeles-Long Beach, CA

New York, NY

Environmental Quality-Income Tradeoff Functions (33 SMSAs):

Atlanta, GA

Austin, TX

Bakersfield, CA

Baltimore, MD

Baton Rouge, LA

Boston, MA

Buffalo, NY

Chicago, IL

Cincinnati, OH-KY-IN

Cleveland, $\mathrm{OH}$

Dallas, TX

Dayton, $\mathrm{OH}$

Denver, CO

Detroit, MI

Hartford, CT

Houston, TX

Indianapolis, IN
Kansas City, MO-KS

Lancaster, PA

Los Angeles-Long Beach, CA

Milwaukee, WI

Minneapolis-St. Paul, MN

Nashville-Davidson, TN

New York, NY

Orlando, FL

Philadelphia, PA-NJ

Pittsburgh, PA

St. Louis, MO-IL

San Diego, CA

San Francisco-Oakland, CA

Seattle-Everett, WA

Washington, DC-MD-VA

Wichita, KS 